\title{
Mobilidade do Sulfentrazone em Solos com Diferentes Características Físicas e Químicas ${ }^{1}$
}

\author{
Mobility of Sulfentrazone in Soils with Different Physical and Chemical Characteristics
}

\author{
FAUSTINO, L.A. ${ }^{2}$, FREITAS, M.A.M. ${ }^{3}$, PASSOS, A.B.R.J. ${ }^{4}$, SARAIVA, D.T. ${ }^{2}$, FARIA, A.T. ${ }^{2}$, \\ SILVA, A.A. ${ }^{2}$ e FERREIRA, L.R. ${ }^{2}$
}

\begin{abstract}
RESUMO - O conhecimento dos fatores que influenciam a lixiviação dos herbicidas no solo é fundamental para sua utilização de forma segura, do ponto de vista técnico e ambiental. Neste trabalho, avaliou-se a mobilidade do sulfentrazone em quatro solos provenientes de uma área de reflorestamento da região Sul do Brasil (Planossolo Háplico, Argissolo Vermelho, Cambissolo Húmico e Neossolo Regolítico) e um Latosso Vermelho-Amarelo da Zona da Mata de Minas Gerais. As amostras de solo foram coletadas na profundidade de $0-20 \mathrm{~cm}$ e caracterizadas física e quimicamente. Os substratos foram colocados em colunas e, posteriormente, aplicou-se, nos topos delas, $1,0 \mathrm{~kg} \mathrm{ha}^{-1}$ do herbicida, seguido de uma chuva simulada de $60 \mathrm{~mm}$. Após a drenagem da água, foram semeadas ao longo da coluna sementes da espécie Sorghum bicolor, como planta bioindicadora da presença do sulfentrazone; 21 dias após o plantio, foi realizada a avaliação visual da intoxicação das plantas de sorgo e a coleta da parte aérea delas para determinação da matéria seca. O delineamento utilizado foi o inteiramente casualizado, em esquema de parcelas subdivididas. As colunas preenchidas com cada um dos solos constituíram as parcelas, e as 10 profundidades da coluna (0-5, 5-10, $10-15,15-20,20-25,25-30,30-35,35-40,40-45$ e $45-50 \mathrm{~cm}$ ), as subparcelas, mais uma testemunha sem herbicida para cada solo. Os teores de argila e matéria orgânica e o pH de cada solo influenciaram na mobilidade do sulfentrazone; solos com menores teores de argila e matéria orgânica apresentaram maior potencial de lixiviação desse herbicida.
\end{abstract}

Palavras-chave: degradação, bioindicador, matéria orgânica.

\begin{abstract}
Knowledge of factors that influence the leaching of herbicides in the soil is essential to use these products safely from a technical and environmental perspective. This study evaluated the mobility of sulfentrazone in four soils from southern Brazil (Haplic Planosol, Red Argisol, Humic Cambisol and Entisol) and a Red-Yellow Latosol from the Zona da Mata region in the state of Minas Gerais. Soil samples were collected at a depth of $0-20 \mathrm{~cm}$ and characterized physically and chemically. The substrates were placed in columns, and $1 \mathrm{~kg} \mathrm{ha}^{-1}$ of the herbicide was subsequently applied on top of them, followed by a simulated rainfall of $60 \mathrm{~mm}$. After draining the water, Sorghum bicolor seeds were sown along the column, as bioindicators of the presence of sulfentrazone; 21 days after planting, the presence of the sorghum plants was assessed visually, and the shoots were collected for determination of dry matter. The experimental design was completely randomized in subdivided plots, whereas the columns filled with each of the five soils were the main plots and the 10 column depths (0-5, 5-10, 10-15, 15-20, 20-25, 25-30, 30-35, 35-40, 40-45 and 45-50 cm) were the subplots. There was a herbicide-free control for each soil. Clay content, organic matter and $p H$ of each soil influenced the mobility of sulfentrazone, and soils with lower clay and organic matter levels showed higher potential of leaching of sulfentrazone.
\end{abstract}

Keywords: degradation, bioindicator, organic matter.

1 Recebido para publicação em 26.5.2015 e aprovado em 1.7.2015.

2 Universidade Federal de Viçosa, Viçosa-MG, Brasil, <lais.faustino@ufv.br>; ${ }^{3}$ Instituto Federal de Educação Ciência e Tecnologia Goiano, IF GOIANO, Posse-GO, Brasil; ${ }^{4}$ Universidade Federal do Espírito Santo, Alegre-ES, Brasil. 


\section{INTRODUÇÃO}

Os herbicidas, aplicados em pré e/ou pós-emergência das plantas daninhas, acabam alcançando o solo, podendo causar danos às culturas subsequentes, à fauna e à flora do solo, além da contaminação de águas superficiais e subterrâneas (Celis et al., 2005; Santos et al., 2010). Ao atingirem o solo, inicia-se o processo de redistribuição e degradação deles, que pode ser curto, como o que ocorre com algumas moléculas simples e não persistentes, ou perdurar por meses ou anos, como ocorre com compostos altamente persistentes (Filizola et al., 2002; Silva \& Silva, 2007).

O potencial de contaminação do lençol freático por herbicidas ou a sua permanência nas camadas superficiais do solo dependem, principalmente, de sua mobilidade no perfil do solo, a qual está diretamente vinculada à sua capacidade de sorção e inversamente à degradação (Vivian et al., 2006). A lixiviação é a principal forma de transporte de moléculas solúveis em água e não voláteis no solo e depende das características físico-químicas do agrotóxico e do solo, além das condições climáticas da região onde foi aplicado (Oliveira, 2011). De maneira geral, a lixiviação do sulfentrazone aumenta com o aumento do indice pluvial mesmo em solos onde sua mobilidade é baixa (Monquero et al., 2010). A lixiviação em pequena escala é fundamental para incorporação superficial de herbicidas aplicados em pré-emergência, possibilitando que estes atinjam sementes ou plantas em germinação. Todavia, em excesso, esse fenômeno pode carreá-los para camadas do solo mais profundas, limitando sua ação e tornando-os possiveis contaminadores do lençol freático (Monquero et al., 2008).

Quando os herbicidas são lixiviados para as camadas mais profundas do solo, terão seu tempo de permanência no ambiente prolongado. Esse fato pode ser atribuído à menor atividade microbiológica encontrada nas camadas mais profundas do solo (Sarmah et al., 1998; Prata et al., 2001).

Entre os diversos herbicidas que apresentam longa persistência no solo e muito utilizados no Brasil, destaca-se o sulfentrazone
[N-[2,4-dichloro-5-[4-(difluorometil)-4,5dihidro-3-metil-5-oxo-1 H-1,2,4-triazol-1-il] fenil] metanosulfonamida]. Pertencente ao grupo das triazolonas, ele é inibidor da enzima protoporfirinogênio oxidase (PROTOX), a qual é responsável pela oxidação do protoporfirinogênio à protoporfirina IX, na biossíntese da clorofila. Possui atividade em pré e pós-emergência, sendo recomendado para controle de plantas daninhas no pósplantio da cultura do eucalipto (ANVISA, 2011). Apresenta meia-vida estimada no solo entre 110 e 280 dias, variando de acordo com as condições edafoclimáticas locais, sendo a atividade microbiológica seu mecanismo inicial de degradação (Grey et al., 2000; Polubesova et al., 2003; Vivian et al., 2006 ). O sulfentrazone apresenta pKa a 6,56 e Kow $=1,48$, solubilidade em água de $490 \mathrm{mg} \mathrm{L}^{-1}$ e pressão de vapor de $1 \times 10^{-9} \mathrm{~mm} \mathrm{Hg}$ a $25^{\circ} \mathrm{C}$. No solo, sua mobilidade é moderada em razão de apresentar baixa sorção (Koc médio $=43$ ) (Rodrigues \& Almeida, 2005).

Considerando a grande diversidade de solos e condições climáticas no Brasil e a longa persistência do sulfentrazone no ambiente, estudos sobre o comportamento desse herbicida nos solos tropicais são de grande relevância para definir, no futuro, modelos que permitam recomendações desse herbicida de modo seguro, quanto à eficiência no controle das plantas daninhas e ao lado ambiental. Neste trabalho, objetivou-se avaliar a mobilidade do sulfentrazone em solos que possuem diferentes características físicas e químicas.

\section{MATERIAL E MÉTODOS}

O experimento foi realizado em casa de vegetação, no Departamento de Fitotecnia da Universidade Federal de Viçosa. Foram utilizadas amostras de quatro solos provenientes de áreas de reflorestamento da região Sul do Brasil (Planossolo Háplico, Argissolo Vermelho, Cambissolo Húmico e Neossolo Regolítico) e um Latossolo Vermelho-Amarelo proveniente da Zona da Mata mineira. Todas as amostras de solo foram coletadas na profundidade de 0 a $20 \mathrm{~cm}$, destorroadas, secas ao ar, peneiradas em malha de $4 \mathrm{~mm}$ e, posteriormente, caracterizadas física e quimicamente (Tabelas 1 e 2). 
Tabela 1 - Características químicas dos solos: Planossolo Háplico, Argissolo Vermelho, Cambissolo Húmico, Neossolo Regolítico e Latossolo Vermelho-Amarelo, avaliados nos experimentos

\begin{tabular}{|c|c|c|c|c|c|c|c|c|c|c|c|c|c|c|}
\hline \multirow{2}{*}{ Solo } & \multirow{2}{*}{$\frac{\mathrm{pH}}{\left(\mathrm{H}_{2} \mathrm{O}\right)}$} & $\mathrm{P}$ & $\mathrm{K}$ & $\mathrm{Ca}$ & $\mathrm{Mg}$ & $\mathrm{Al}$ & $\mathrm{H}+\mathrm{Al}$ & SB & t) & $(\mathrm{T})$ & $\mathrm{V}$ & $\mathrm{m}$ & \multirow{2}{*}{$\frac{\mathrm{MOO}}{\left(\operatorname{dag~g}^{-1}\right)}$} & \multirow{2}{*}{$\frac{\text { P-rem }}{\left(\mathrm{mg} \mathrm{L}^{-1}\right)}$} \\
\hline & & \multicolumn{2}{|c|}{$\left.(\mathrm{mg} \mathrm{dm})^{-3}\right)$} & \multicolumn{7}{|c|}{$\left(\mathrm{cmol}_{\mathrm{c}} \mathrm{dm}^{-3}\right)$} & \multicolumn{2}{|c|}{$\begin{array}{c}1 \\
(\%)\end{array}$} & & \\
\hline Planossolo & 5,6 & 3,2 & 11 & 0,3 & 0,2 & 0,3 & 1,82 & 0,53 & 0,83 & 2,35 & 23 & 36 & 1,1 & 43,9 \\
\hline Argissolo & 5,2 & 1,5 & 27 & 1,2 & 0,6 & 2,1 & 6,77 & 1,87 & 3,97 & 8,64 & 22 & 53 & 2,1 & 20,8 \\
\hline Cambissolo & 5,1 & 5,9 & 99 & 0,9 & 0,5 & 1,7 & 6,77 & 1,65 & 3,35 & 8,42 & 20 & 51 & 2,3 & 26,6 \\
\hline Neossolo & 5,1 & 9,1 & 115 & 3,3 & 0,7 & 0,7 & 8,09 & 4,29 & 4,99 & 12,38 & 35 & 14 & 5,1 & 23,5 \\
\hline Latossolo & 4,3 & 1,5 & 40 & 1,3 & 0,2 & 0,5 & 4,79 & 1,60 & 2,10 & 6,39 & 25 & 24 & 2,4 & 26,4 \\
\hline
\end{tabular}

Análises realizadas no Laboratório de Análises de Solo Viçosa, segundo a metodologia da Empresa Brasileira de Pesquisa Agropecuária EMBRAPA (1997). (t) = capacidade de troca catiônica efetiva; $\mathrm{V}=$ saturação por bases; $\mathrm{m}=$ saturação por $\mathrm{Al}{ }^{+3}$; $\mathrm{MO}=$ matéria orgânica.

Tabela 2 - Características físicas dos solos: Planossolo Háplico, Argissolo Vermelho, Cambissolo Húmico, Neossolo Regolítico e Latossolo Vermelho-Amarelo, avaliados nos experimentos

\begin{tabular}{|l|r|r|r|l|}
\hline \multirow{2}{*}{ Solo } & Areia & Silte & Argila & \multirow{2}{*}{ Classe textural } \\
\cline { 2 - 4 } & \multicolumn{3}{|c|}{$(\%)$} & \\
\hline Planossolo & 87 & 4 & 9 & Areia Franca \\
\hline Argissolo & 42 & 20 & 38 & Franco-Argiloso \\
\hline Cambissolo & 62 & 12 & 26 & Franco-argiloarenoso \\
\hline Neossolo & 51 & 17 & 32 & Franco-Argiloso \\
\hline Latossolo & 35 & 11 & 54 & Argiloso \\
\hline
\end{tabular}

Análises realizadas no Laboratório de Análises de Solos Viçosa Determinações realizadas pelo método da pipeta (Embrapa, 1997; Ruiz, 2005).

Para a realização deste trabalho, foram utilizadas colunas de cloreto de polivinil (PVC) de $10 \mathrm{~cm}$ de diâmetro x $50 \mathrm{~cm}$ de altura, seccionadas transversalmente a cada $5 \mathrm{~cm}$ ao longo do seu comprimento. O interior delas foi parafinado com o objetivo de reduzir a percolação da água pelo fluxo preferencial entre o solo e o PVC. As colunas foram montadas, recebendo uma tampa lateral removivel, e uma das extremidades (fundo) foi vedada com gaze e papel-filtro. Posteriormente, foram preenchidas com as amostras de solo e acondicionadas em posição vertical, em recipiente com água, até que esta atingisse $80 \%$ da altura da coluna, por um período de 48 horas, com intuito de umedecer o solo e eliminar todo o ar aprisionado dentro das colunas, evitando caminhos preferenciais. Em seguida, realizou-se a vedação da parte superior dessas colunas, com filme de polipropileno e papel-alumínio, para que a água não evaporasse; depois disso, elas foram transferidas para a bancada, onde permaneceram na posição vertical, em repouso por mais 72 horas, para drenagem do excesso de água.

A seguir, aplicou-se o herbicida sulfentrazone na parte superior das colunas, na dose de $1,00 \mathrm{~kg} \mathrm{ha}^{-1}$, utilizando um pulverizador pressurizado por $\mathrm{CO}_{2}$ comprimido, equipado com barra com dois bicos TT11002, espaçados de $0,50 \mathrm{~m}$ e com volume de calda de $150 \mathrm{~L} \mathrm{ha}^{-1}$. Doze horas após a aplicação do herbicida, as colunas montadas receberam a simulação de $60 \mathrm{~mm}$ de chuva. Após 72 horas, as colunas foram colocadas na posição horizontal e abertas longitudinalmente, retirando-se a tampa removivel; em seguida, procedeu-se ao seccionamento do solo dentro das colunas, a cada $5 \mathrm{~cm}$.

A separação dos segmentos de solo foi feita com uma lâmina de PVC, no intuito de evitar que o sistema radicular das plantas indicadoras atingisse outras secções. Nessa abertura lateral de cada coluna foram semeadas cinco sementes de Sorghum bicolor, em cada segmento de $5 \mathrm{~cm}$ de solo, para se avaliar a mobilidade do sulfentrazone. O experimento foi realizado no delineamento inteiramente casualizado, em esquema de parcelas subdivididas com quatro repetições. As parcelas foram constituidas pelas colunas de PVC, preenchidas com os solos anteriormente citados, e as subparcelas, pelos diferentes segmentos da coluna (0-5, 5-10, 10-15, 15-20, 20-25, 25-30, 30-35, 35-40, 40-45 e 45-50 cm). Foi utilizada uma testemunha sem herbicida para cada solo. 
A umidade do solo nas colunas durante a realização deste ensaio foi mantida por meio de irrigações diárias, com o objetivo de suprir às plantas a água evapotranspirada. Além das irrigações, nesse período, as plantas foram tratadas com solução nutritiva, no intuito de que a única fonte de redução da massa de matéria seca fosse a aplicação do herbicida.

A avaliação do índice de intoxicação das plantas indicadoras utilizado para interpretar a mobilidade do herbicida na coluna foi feita aos 18 dias após a emergência (DAE), atribuindo-se notas de 0 (ausência de intoxicação) a 100 (morte da planta), de acordo com a escala da EWRC (1964) modificada. Aos $21 \mathrm{DAE}$, as plantas de sorgo foram seccionadas rente ao solo, acondicionadas em sacos de papel e secas em estufa de circulação forçada de ar $\left(70 \pm 2{ }^{\circ} \mathrm{C}\right)$ até atingir peso constante. Posteriormente, foi determinada a massa da matéria seca das plantas indicadoras, em balança analítica com precisão de 0,001 g.

Os valores obtidos de fitointoxicação e matéria seca da parte aérea das plantas foram comparados aos obtidos na testemunha (sem aplicação do herbicida); os valores de massa da matéria seca das plantas de sorgo (MS) foram transformados para porcentagem em relação à MS da testemunha, adotando-se $100 \%$ para MS da testemunha. Para interpretação dos resultados, os dados obtidos no bioensaio foram submetidos à análise de variância e de regressão. Na escolha dos modelos foi levada em consideração a resposta biológica e os coeficientes de determinação.

\section{RESULTADOS E DISCUSSÃO}

Independentemente das características físicas e químicas, em todos os solos constatou-se a presença do herbicida sulfentrazone nos primeiros $5 \mathrm{~cm}$ de profundidade. Isso foi evidenciado pelos menores valores da massa de matéria seca das plantas cultivadas nesse segmento da coluna (Figura 1), com elevados indices de intoxicação nas plantas indicadoras (Figura 2).

O Planossolo apresentou índice de intoxicação visual superior a $15 \%$ e acúmulo de biomassa em relação à testemunha inferior a $80 \%$ em todo o comprimento da coluna (Figuras 1 e 2).

Planta Daninha, Viçosa-MG, v. 33, n. 4, p. 795-802, 2015
Para o Argissolo Vermelho, observou-se a presença do sulfentrazone nos primeiros $15 \mathrm{~cm}$ (Figura 1), apresentando índices de intoxicação visual superiores a $80 \%$. No Cambissolo húmico houve deslocamento do sulfentrazone até os primeiros $20 \mathrm{~cm}$ no perfil do solo (Figuras 1 e 2), mesmo esses substratos apresentando teores semelhantes de matéria orgânica ( $\mathrm{MO}=2,1$ e 2,3 dag kg-1, respectivamente) e valores idênticos de $\mathrm{pH}$ (Tabela 1).

O Latossolo Vermelho-Amarelo apresentou maior teor de argila (54\%) e teor de matéria orgânica de 2,4 dag $\mathrm{kg}^{-1}$, semelhante aos valores observados para Argissolo e Cambissolo, porém observou-se para esse substrato movimentação do sulfentrazone até os $25 \mathrm{~cm}$ de profundidade (Figuras 1 e 2), com intoxicação das plantas indicadoras em niveis superiores a $82,5 \%$ e redução da massa de matéria seca para $9,76 \%$ no primeiro segmento $(0-5 \mathrm{~cm})$ e $27,30 \%$ no quinto segmento $(20-25 \mathrm{~cm}) \mathrm{da}$ coluna com Latossolo Vermelho-Amarelo, em relação à testemunha sem aplicação do herbicida.

No Neossolo Regolítico, observou-se mobilidade do sulfentrazone nos $20 \mathrm{~cm}$ iniciais do perfil do solo (Tabelas 3 e 4 e Figuras 1 e 2). No entanto, dos solos estudados, o Neossolo apresentou menores reduções de matéria seca e menor intoxicação das plantas de sorgo ao longo de todo o comprimento da coluna, sendo esse índice inferior a $72,5 \%$ inclusive no primeiro segmento $(0-5 \mathrm{~cm})$. Ele apresentou teor de matéria orgânica superior ao dobro do encontrado em todos os demais solos (5,1 dag kg-1) e maior CTC efetiva (4,99 $\left.\mathrm{cmol}_{\mathrm{c}} \mathrm{dm}^{-3}\right)$ (Tabela 1$)$.

Quando se comparou a resposta da planta indicadora nos diferentes solos, verificou-se que no Planossolo Háplico ocorreram sintomas de intoxicação e redução no acúmulo de massa de matéria seca em todos os dez segmentos da coluna, o que indicou a lixiviação do sulfentrazone ao longo de todos os $50 \mathrm{~cm}$ da coluna. Nos demais solos observou-se decréscimo dos índices de intoxicação e aumento no acúmulo da massa de matéria seca da planta indicadora em segmentos de solo oriundos de maior profundidade na coluna, indicando a ocorrência de menor mobilidade do sulfentrazone nestes solos (Figuras 1 e 2). 

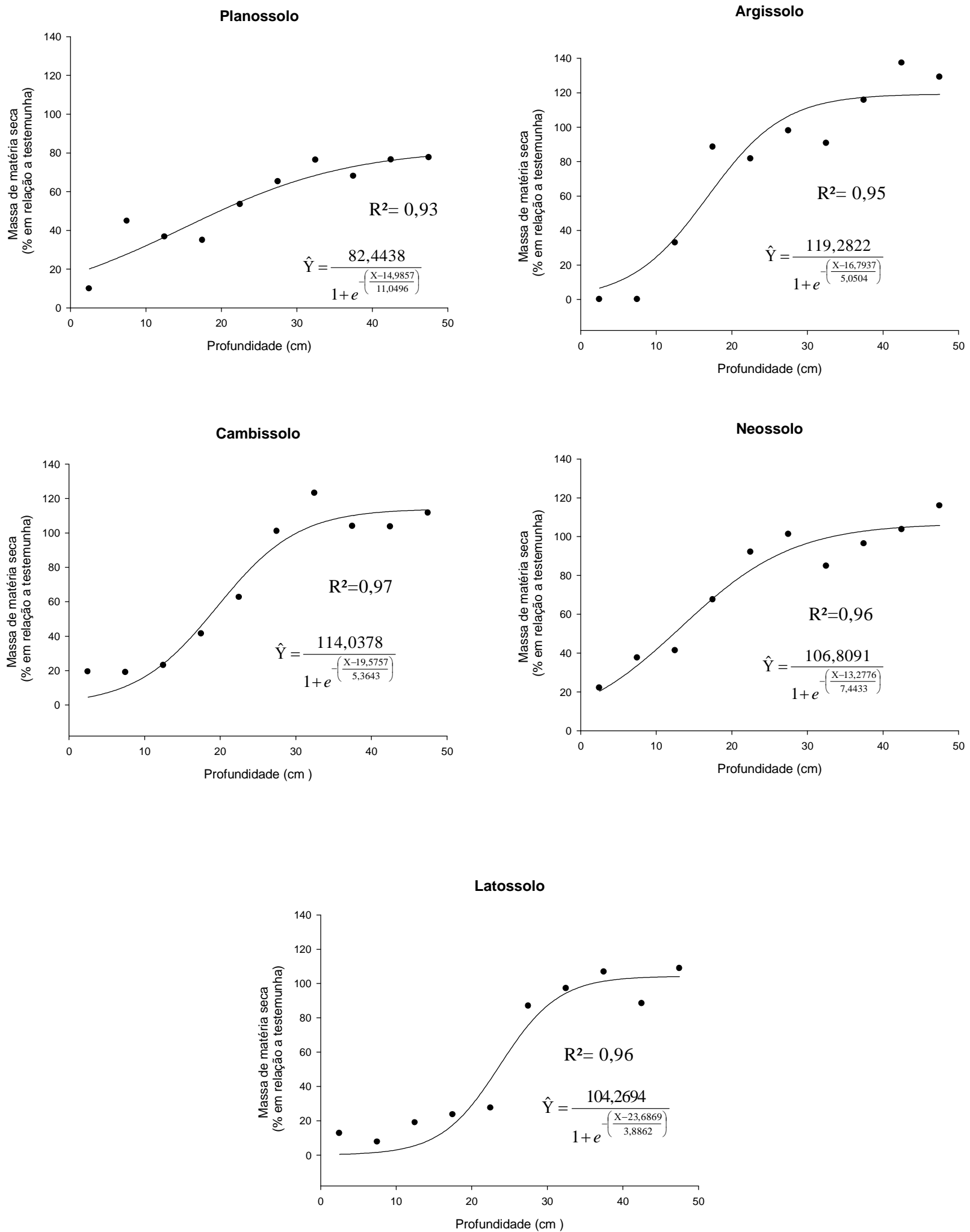

Figura 1 - Porcentagem de massa de matéria seca de plantas de sorgo, em relação à testemunha, cultivadas em diferentes solos, em diferentes profundidades nas colunas, após aplicação do sulfentrazone e submetidas à chuva de 60 mm. 
Planossolo

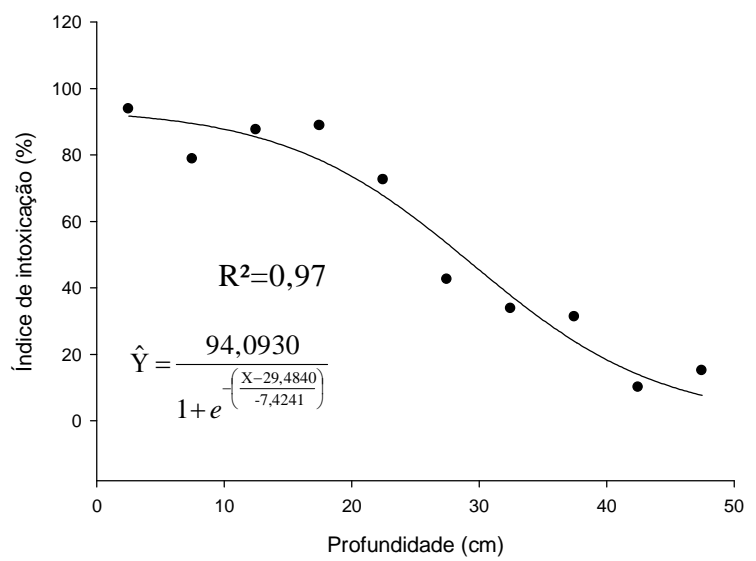

Cambissolo

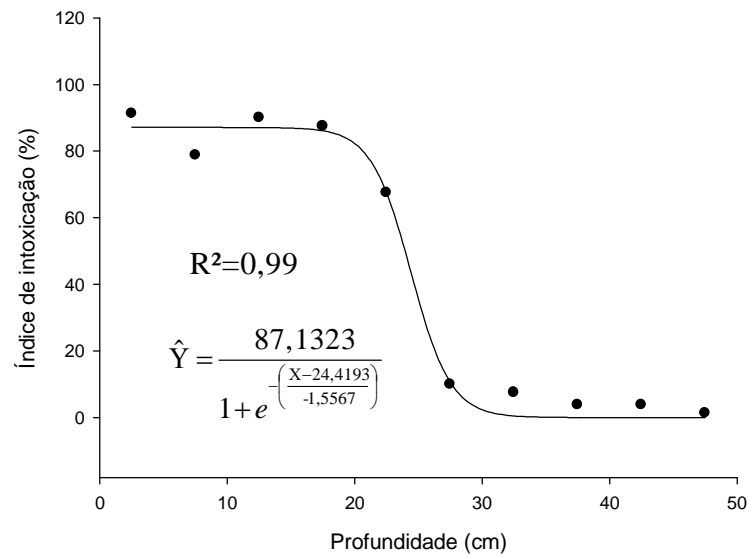

Argissolo

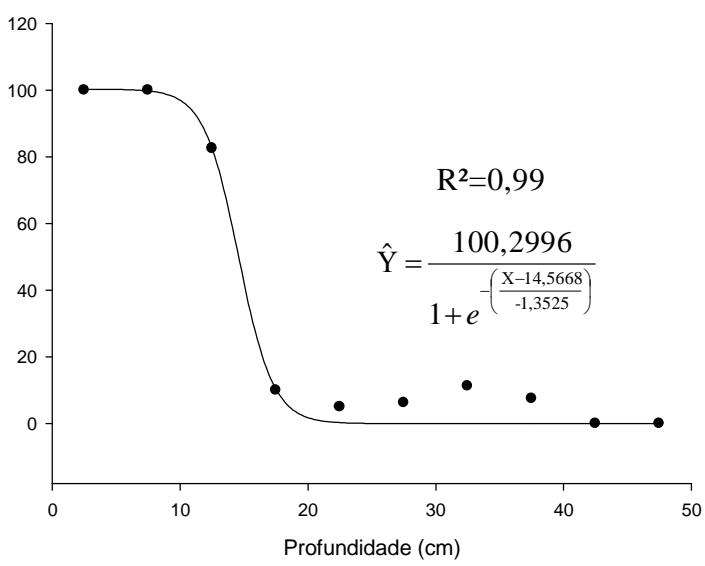

Neossolo

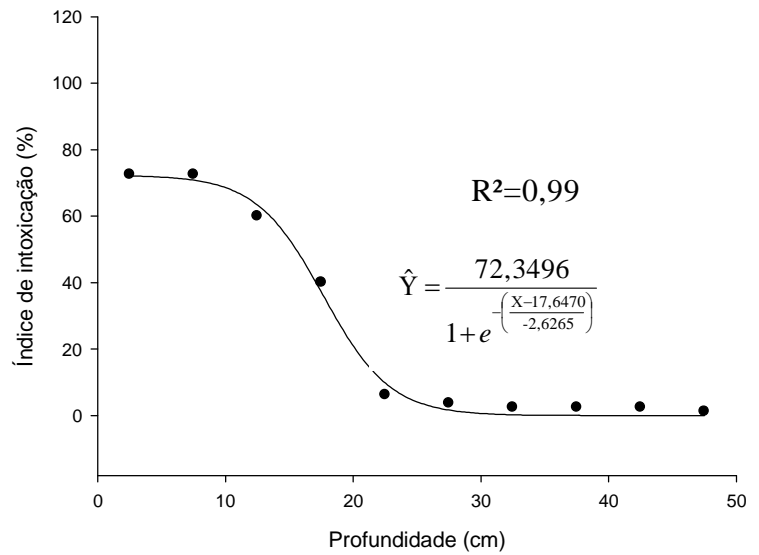

Latossolo

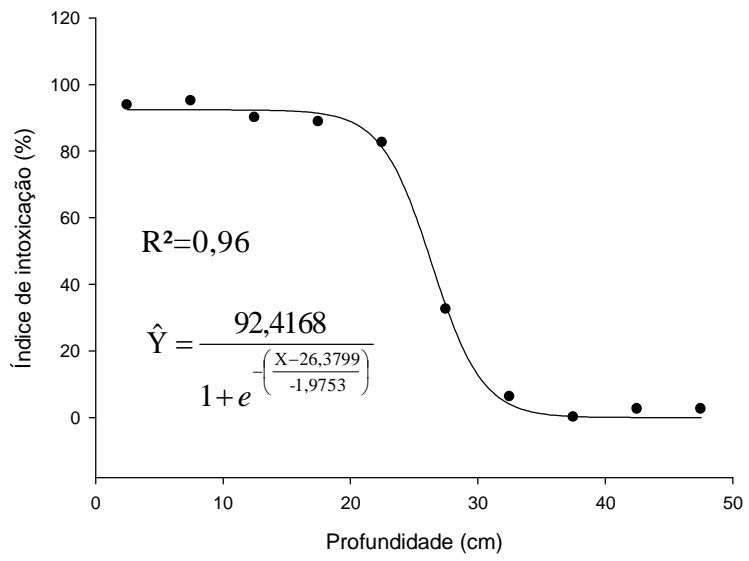

Figura 2 - Índice de intoxicação de plantas de sorgo cultivadas em diferentes solos, em diferentes profundidades nas colunas, após aplicação do sulfentrazone e submetidas à chuva de $60 \mathrm{~mm}$. 
A elevada movimentação do sulfentrazone no Planossolo pode ser explicada pelas características químicas e físicas deste, pelo baixo teor de matéria orgânica, igual a 1,1 dag $\mathrm{kg}^{-1}$ (Tabela 1), e pelo alto teor de areia, $87 \%$ (Tabela 2). A movimentação das moléculas é dependente dos atributos físicos, químicos e biológicos do solo, como textura, mineralogia, teor de matéria orgânica, pH, CTC, atividade microbiana, entre outros (Monquero et al., 2010).

A movimentação do sulfentrazone em colunas de $50 \mathrm{~cm}$ preenchidas com Chernossolo (textura arenosa) foi afetada pela percolação da água; o herbicida reduziu o desenvolvimento de plantas de sorgo cultivadas em amostras coletadas até as maiores profundidades da coluna (Rossi et al., 2005). Além disso, os teores de matéria orgânica e $\mathrm{pH}$ dos solos são algumas das principais características relacionadas à mobilidade de herbicidas no solo (Prata et al., 2003; Rossi et al., 2005). Entretanto, o comportamento distinto com relação à movimentação do herbicida apresentado pelo Argissolo e Cambissolo, provavelmente, ocorreu devido às suas características físicas: o Argissolo apresenta $42 \%$ de areia, $20 \%$ de argila e textura franco-argilosa, e o Cambissolo, $62 \%$ de areia, $12 \%$ de argila e textura franco-argiloarenosa (Tabela 2). A mobilidade do sulfentrazone é maior em solos com maior porcentagem de areia, em comparação a solos mais argilosos (Rossi et al., 2005).

O potencial de lixiviação do Latossolo Vermelho-Amarelo, superior ao dos demais solos com teor de matéria orgânica similar, pode ser explicado pelo menor valor de $\mathrm{pH}(4,3)$ encontrado nesse substrato, aliado ao tipo de argila, 1:1 (caulinítica), predominante em latossolos intemperizados (Melo et al., 2001; Resende et al., 2005). Argilas cauliníticas em valores de $\mathrm{pH}$ baixo, como na presente situação, sofrem protonação de parte de seus grupamentos, adquirindo cargas positivas (Hu \& Liu, 2003), e a eficiência do sulfentrazone decresce no controle de plantas daninhas, principalmente na presença de teores maiores de matéria orgânica e valores de $\mathrm{pH}$ próximos ao seu $\mathrm{pKa}$, indicando menor quantidade do herbicida presente na solução do solo para exercer sua ação (Wehtje et al., 1995). Como o processo de lixiviação de compostos químicos é influenciado pela capacidade de sorção deles aos coloides orgânicos e minerais dos solos e dependente das características físico-químicas do composto e das características de solo e clima (Inoue et al., 2003), a menor sorção do sulfentrazone resultou em maior mobilidade do herbicida e presença deste até a metade da coluna de $50 \mathrm{~cm}$ preenchida com Latossolo Vermelho-Amarelo.

O teor e o tipo de matéria orgânica do solo influenciam o movimento descendente dos herbicidas (Prata et al., 2003; Rossi et al., 2005) e a sorção do sulfentrazone. Outro fator é a CTC dos solos: em solos com maiores teores de matéria orgânica e CTC efetiva ocorre maior sorção do herbicida (Kerr et al., 2004; Vivian et al., 2006). Solos que apresentam maior potencial de sorção, consequentemente, estão menos suscetíveis à ocorrência do processo de lixiviação.

Conclui-se que a movimentação do sulfentrazone nos solos é altamente influenciada por suas características químicas e físicas, principalmente o teor de argila e a matéria orgânica. Dessa forma, torna-se necessário o conhecimento detalhado do tipo de solo para realizar recomendações técnicas desse herbicida, evitando os riscos de lixiviação e contaminação de lençóis freáticos e cursos de água. O sulfentrazone é muito móvel em solos arenosos e com baixo teor de matéria orgânica, podendo atingir camadas profundas do solo, reduzindo assim a eficácia do controle de plantas daninhas. Por esses motivos, o sulfentrazone não deve ser recomendado para solos com tais características físicas e químicas.

\section{LITERATURA CITADA}

AGÊNCIA NACIONAL DE VIGILÂNCIA SANITÁRIA ANVISA. Disponível em: <http://portal.anvisa.gov.br/wps/ portal/anvisa/home/agrotoxicotoxicologia $>$. Acesso em: 5 maio 2011.

CELIS, R. et al. Sorption and leaching behaviour of polar aromatic acids in agricultural soils by batch and column leaching tests. Eur. J. Soil Sci., v. 56, n. 3, p. 287-297, 2005.

EMPRESA BRASILEIRA DE PESQUISA AGROPECUÁRIA - EMBRAPA. Centro Nacional de Pesquisa de Solos (Rio de Janeiro, RJ). Manual de métodos de análise de solos. 2.ed. Rio de Janeiro: 1997. 212 p. 
EUROPEAN WEED RESEARCH COUNCIL - EWRC. Report of the $3^{\text {rd }}$ and $4^{\text {th }}$ meetings of EWRC - Comittee of Methods in Weed Research. Weed Res., v. 4, n. 1, p. 88, 1964.

FILIZOLA, H. F. et al. Monitoramento e avaliação do risco de contaminação por pesticidas em água superficial e subterrânea na região de Guairá. Pesq. Agropec. Bras., v. 37, n. 5, p. 659-667, 2002.

GREY, T. L. et al. Behavior of sulfentrazone in ionic exchange resins, electrophoresis gels, and cation-saturated soils.

Weed Sci., v. 48, n. 2, p. 239-247, 2000.

HU, Y.; LIU, X. Chemical composition and surface property of kaolins. Miner. Eng. v. 16, n. 11, p. 1279-1284, 2003.

INOUE, M. H. Critérios para avaliação do potencial de lixiviação de herbicidas comercializados no estado do Paraná. Planta Daninha, v. 21, n. 2, p. 313-323, 2003.

KERR, G. W. et al. Soil pH and cation exchange capacity effects sunflower tolerance to sulfentrazone. Weed Technology, v. 18, n. 2, p. 243-247, 2004.

MELO, V. F. et al. Chemical and mineralogical properties of kaolinite - rich Brasilian soils. Soil Sci. Soc. Am. J., v. 65, n. 4, p. 1324-1333, 2001.

MONQUERO, P. A. et al. Lixiviação e persistência dos herbicidas sulfentrazone imazapic. Planta Daninha, v. 28, n. 1, p. 185-195, 2010.

MONQUERO, P. A. et al. Mobilidade e persistência de herbicidas aplicados em pré-emergência em diferentes solos. Planta Daninha, v. 26, n. 1, p. 411-417, 2008.

OLIVEIRA, M. F. Comportamento dos herbicidas no ambiente. In: OLIVEIRA JÚNIOR, R. S.; CONSTANTIN, J.; INOUE, M. H. (Ed.). Biologia e manejo de plantas daninhas. Curitiba: Omnipax, 2011. p. 263-304.

PRATA, F. et al. Glyphosate sorption and desorption in soils with different phosphorous levels. Sci. Agric., v. 60, n. 1, p. 175-180, 2003.
PRATA, F. et al. Degradação e sorção de ametrina em dois solos com aplicação de vinhaça. Pesq. Agropec. Bras., v. 36, n. 7, p. 975-981, 2001.

POLUBESOVA, T. et al. Sulfentrazone adsorbed on micellemontmorillonite complexes for slow release in soils. J. Agric. Food Chem., v. 51, n. 11, p. 3410-3414, 2003.

RESENDE, M. et al. Mineralogia de solos brasileiros: interpretação e aplicação. Lavras: Universidade Federal de Lavras, 2005. 192 p.

RODRIGUES, B. N.; ALMEIDA, F. S. (Ed.). Guia de herbicidas. Londrina: 2005. 591 p.

ROSSI, C. V. S. et al. Mobilidade do sulfentrazone em Latossolo Vermelho e em Chernossolo. Planta Daninha, v. 23, n. 3, p. 701-710, 2005.

RUIZ, H. A. Incremento da exatidão da análise granulométrica do solo por meio da coleta da suspensão (silte + argila).

R. Bras. Ci. Solo, v. 29, n. 2, p. 297-300, 2005.

SANTOS, L. B. O. Determination of picloram in waters by sequential injection chromatography with UV detection. J. Braz. Chem. Soc., v. 21, n. 8, p. 1401-1592, 2010.

SARMAH, A. et al. Fate and behaviour of triasulfuron, metsulfuron-methyl and chlorsulfuron in the Australian soil environment: a review. Austr. J. Agric. Res., v. 49, n. 5, p. 775-790, 1998.

SILVA, A. A.; SILVA, J. F. (Ed.). Tópicos em manejo de plantas daninhas. Viçosa, MG: Universidade Federal de Viçosa, 2007. 367 p.

VIVIAN, R. et al. Persistência de sulfentrazone em Argissolo Vermelho-Amarelo cultivado com cana-de-açúcar.

Planta Daninha, v 24, n. 4, p. 741-750, 2006.

WEHTJE, G. et al. Soil effects of sulfentrazone. Proc. South. Weed Sci. Soc., v. 48, p. 224, 1995. 